\title{
Super-twisting sliding mode controllers based on D-PSO optimization for temperature control of an induction cooking system
}

\author{
Abdeldjalil Abdelkader Mekki ${ }^{1}$, Abdelkader Kansab ${ }^{2}$, Mohamed matallah ${ }^{3}$, Zinelaabidine Boudjema ${ }^{4}$, \\ Mouloud Feliachi ${ }^{5}$ \\ ${ }^{1,2,4}$ Department Laboratory L.G.E.E.R, University of Hassiba Benbouali, Algeria \\ ${ }^{3}$ University of Djilali Bounaama, Khemis miliana, Algeria \\ ${ }^{5}$ IREENA-IUT, CRTT, Bd de l'université, France
}

\begin{tabular}{l} 
Article Info \\
\hline Article history: \\
Received Apr 10, 2019 \\
Revised Nov 8, 2019 \\
Accepted Dec 22, 2019 \\
\hline
\end{tabular}

Keywords:

Induction cooking

Magneto- thermal

Finite element method

Particle swarm optimization

Super-twisting sliding mode

\begin{abstract}
In this study, we perform the control of the temperature evolution versus time of induction cooking system using a super twisting sliding mode control (STSMC) based on Dynamic Particle Swarm Optimization (D-PSO). First, we will determine the evolution of the temperature in the middle of the pan bottom using the FEM method. The found temperature exceeds the limit of the desired cooking temperature $\left(150-200^{\circ} \mathrm{C}\right)$. Second, to limit temperature increase, a (ST-SMC) method combined with a (D-PSO) algorithm is used to get the desired temperature. Particles Swarm Optimization (D-PSO) method is used to optimize the parameters of the gain of (ST-SMC) and improve its performance. The simulation results show that the use of the optimized super twisting sliding mode controller helps to achieve a desired value of cooking.
\end{abstract}

This is an open access article under the CC BY-SA license.

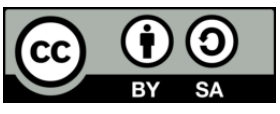

\section{Corresponding Author:}

Abdeldjalil Abdelkader Mekki, Departement of Electrotechnic, Laboratory L.G.E.E.R, University of Hassiba Benbouali, Chlef 02000, Algeria Email: a.abdelkadermekki@univ-chlef.dz

\section{INTRODUCTION}

Nowadays, Domestic induction cookers (IC) are more and more used due to its heating rapidity, safety and energetic efficiency. The mechanism of (IC) contains an inductor which is placed on a support with a material of ferrite, and the pan which is a ferromagnetic metal disc, as depicted in Figure 1 . The current density generated by the inductor produces a varying magnetic field, which induces eddy currents on the pan bottom cause it heating by Joule effect. [1].

On the other hand, the variation control of the temperature in the pan's bottom is difficult because of the nonlinearity of the characteristics magnetic and electric of ferromagnetic material of the pan [2], and the high frequency current of the inductor ,that's why it's not easy to obtain an accurate mathematical model that can be used for our studied device [3], For this reason, our work focuses on controlling the cooking temperature by implementing a technique called super twisting sliding mode control (ST-SMC), the aim of this technique is to select an appropriate input current which can give suitable cooking temperature.

The super-twisting sliding mode algorithms is one of the most important approaches and the most widely used Sliding mode control (ST-SMC) designed to work and control of nonlinear systems having an important uncertainty conditions $[4,5]$. The principal idea of the super-twisting sliding mode control is to force the sliding variable and its derivative to zero in a finite time in order to be able to remove the chattering 
effect due to the discontinuous control action while retaining the key benefits of the classical sliding mode control $[6,7]$.

The choice of gain parameters of the super twisting sliding mode control has an influence on the controller performance, where optimal gain parameters guarantee the stability and robustness of the system and give a fast response. Various optimization techniques are used to optimize gain parameters of the sliding mode controller, such as the genetic algorithm and particle swarm optimization [8-11]. In this paper, the super twisting gain parameters are optimized using Dynamic Particle Swarm Optimization (D-PSO) [12]. This algorithm is chosen due to its easy implementation, speed, and because it is a promising tool for designing optimal controllers over other optimization techniques. The simulation results of uncontrolled and controlled models are compared, where the use of (ST-SMC based D-PSO) method is shown to give good results in terms of reliability, and stability performance.

This paper is organised as follows: in section 2, modelling and finite element analysis are presented. The evolution of temperature in the pan's bottom is determined in section 3. A suitable cooking temperature using super twisting sliding mode (ST-SMC) and (D-PSO) technique is presented in section 4 and the results of simulation are shown in section 5. Finally, the conclusion is presented in Section 6.

\section{MAGNETO-THERMAL FINITI ELEMENT ANALYSIS}

To further enhance the performance of the induction cooking hob, it is primordial to determine the evolution of the temperature as a function of time which is at the same time the image of the evolution of the induced currents generated by the inductor. The mathematical model of the induction heating is composed of two parts: the first part is the equation of magneto-dynamics which is based on harmonic time variation, whereas the second is the thermal equation with a transit time variation.

The mathematical model of the physical phenomenon of the induction cooking system is $2 \mathrm{~d}$ axisymmetric. Using the magnetic potential A, it can be modelled by the coupled magneto-thermal formulation [13] given by:

$$
\begin{aligned}
& j \omega \frac{\sigma \bar{A}}{r}-\frac{\partial}{\partial r}\left(\frac{v}{r} \frac{\partial \bar{A}}{\partial r}\right)-\frac{\partial}{\partial z}\left(\frac{v}{r} \frac{\partial \bar{A}}{\partial z}\right)=\bar{J} \\
& \lambda \nabla^{2} T+q=\rho_{m} C_{p} \frac{\partial T}{\partial t} \\
& q=\frac{1}{r^{2}} \sigma \omega^{2} \bar{A} \overline{A^{*}}
\end{aligned}
$$

Where:

$\bar{A} \quad$ is the magnetic vector potential

$r, t \quad$ are the radial distance from the axis and the time respectively.

$\nu, \sigma, \omega \quad$ are the magnetic reluctivity, the electric conductivity, and the angular frequency,respectively

$J \quad$ is the current density and the temperature respectively.

$\lambda, \rho_{m}, C_{p} \quad$ are the thermal conductivity, the masse density, and the specific heat, respectively

The resolution of these last equations with the finite element method requires the use of the boundary conditions in the borders of the pan which are of the Neumann type (4), and the boundary conditions for the electromagnetic equations are of the Dirichlet type (5).

$$
\begin{aligned}
& -\lambda \frac{\partial T}{\partial n}=h\left(T-T_{n}\right) \\
& (\mathrm{A}=0)
\end{aligned}
$$

where :

$\mathrm{h}$ is the convection coefficient

Tn is the ambient temperature

The pan material is made of stainless-steel the properties of which are given in [13].

The convection coefficient $h$ in the pan bottom has a nonlinear value due to the convection effect of the air nearby. In this work, in order to simplify the latter phenomenon we assume that $h$ has constant value along of radius of the pan [14].

Int J Pow Elec \& Dri Syst, Vol. 11, No. 2, June 2020 : 1055 - 1064 


\section{PROCEDURE CALCULATION AND DETERMINATION OF THE TEMPERATURE EVOLUATION}

The proposed model is an induction cooking system, which is composed of three parts. The first one is the pan which is the part to be heated. The second part is the air gap, and the last part is the inductor which has four slots containing the exciting coils as shown in Figure 1 and Figure 2. The geometrical and physical parameters are shown in Table 1 , except the value of the current density which is equal to $\left(2.5 * 10^{6} \mathrm{~A} / \mathrm{m}^{2}\right)$ in this work.

Table 1. Parameters of system

\begin{tabular}{ccc}
\hline Symbole & Magnitude & Quantity \\
\hline $\mathrm{R}$ & Radius of pan & $140 \mathrm{~mm}$ \\
$\mathrm{e}_{1+} \mathrm{e}_{2}$ & Inductor thickness & $3.8 \mathrm{~mm}$ \\
$\mathrm{e}_{3}$ & Gap thickness & $4 \mathrm{~mm}$ \\
$\mathrm{e}_{4}$ & Container thickness & $3 \mathrm{~mm}$ \\
$\mathrm{~d}_{\mathrm{i}}, \mathrm{i}=1 \ldots 9$ & Distances & $15.55 \mathrm{~mm}$ \\
$\mathrm{e}_{2}$ & coils thickness & $2 \mathrm{~mm}$ \\
$\mu_{\mathrm{f}}$ & Ferrite relative & 2500 \\
& permeability & $20^{*} 10^{3} \mathrm{~Hz}$ \\
$\mathrm{f}$ & Frequency & $2.5^{*} 10^{6} \mathrm{~A} / \mathrm{m}^{2}$ \\
$\mathrm{~J}$ & Current density & $26 \mathrm{~W} / \mathrm{m}^{* \circ} \mathrm{K}$ \\
$\lambda$ & Thermal \\
& conductivity & $20 \mathrm{~W} / \mathrm{m}^{2 \circ} \mathrm{C}$ \\
$\mathrm{h}$ & Convection & \\
& coefficient & $7700 \mathrm{Kg} / \mathrm{m}^{3}$ \\
$\rho_{\mathrm{m}}$ & Masse density & $460 \mathrm{~J} / \mathrm{Kg} .{ }^{\circ} \mathrm{C}$ \\
$\mathrm{C}_{\mathrm{p}}$ & Specific heat \\
\end{tabular}

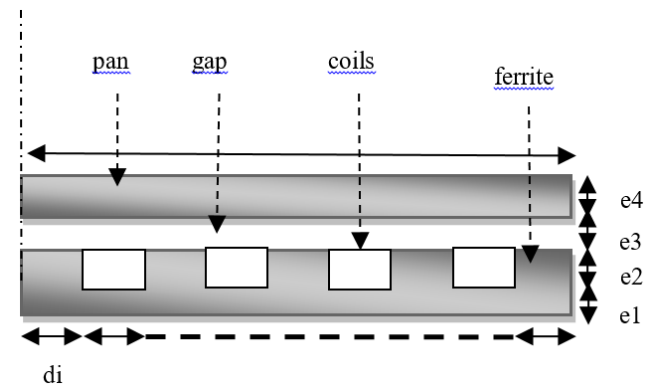

Figure 1. Dimensions of system used

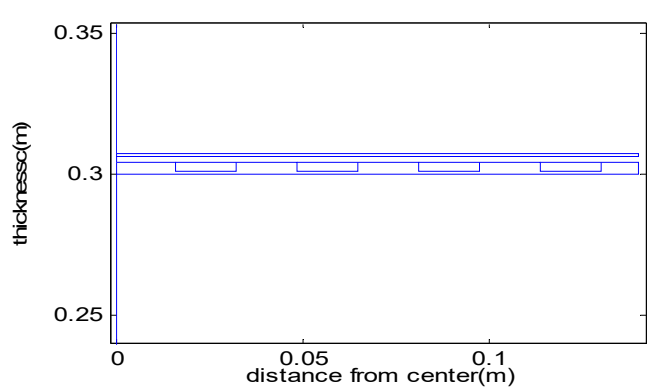

Figure 2. Model system used in the Program

The magneto-thermal calculations of the induction cooking system are given by following steps:

a. Step 1: initialization of the magnetic réluctivity, the electric conductivity, and the temperature $\sigma_{0}, \mu_{0}, T_{0}$

b. Step 2 : calculation of the magnetic vector potential (A) by use of (1).

c. Step 3 : calculation of the heat source density is given by (2) and (3).

d. Step 4 : calculation of the temperature $T$ where we use a time step of 10 (s) .

If $\left(T \leq 750 C^{\circ}\right)$ go back to step 2 or else go to step 5 .

e. Step 5 : display of the results.

The simulation results obtained are shown in Figure 3 and Figure 4. It is clear from those Figures that the temperature evolution on the pan's bottom exceeds the appropriate value of cooking. This is caused by the variation of the electromagnetic properties of the system such as the electrical resistivity $\rho(T)$ and the magnetic permeability $\mu \mathrm{r}(\mathrm{T})$. 


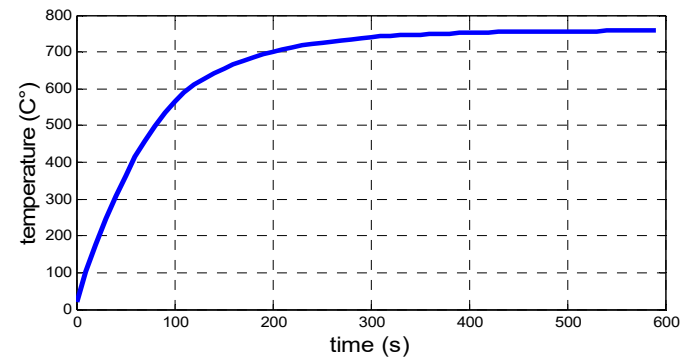

Figure 3. Temperature evolution versus time

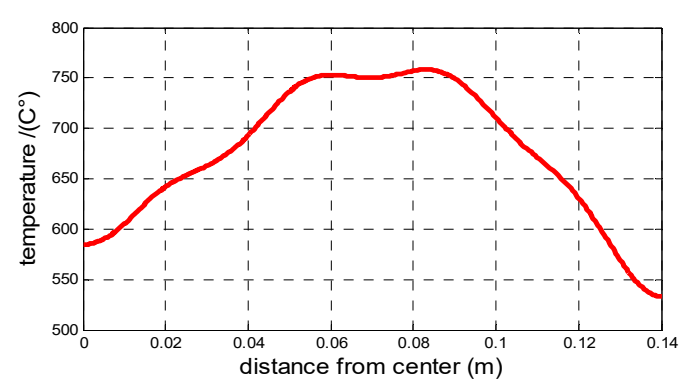

Figure 4. Temperature distribution on pan's bottom

\section{TEMPERATURE REGULATION}

Because the induction cooking system is a coupled nonlinear uncertain system, it's not easy to have an accurate mathematical model that can be used to control the temperature of the pan [3]. For this reason, and in order to control the temperature of the pan and to get an appropriate temperature of cooking, a solution by the use of D-PSO technique is applied to select optimal gain parameters of super twisting sliding mode controller, where the optimized ST-SMC is employed to control the temperature of the device which is shown in figure 5.

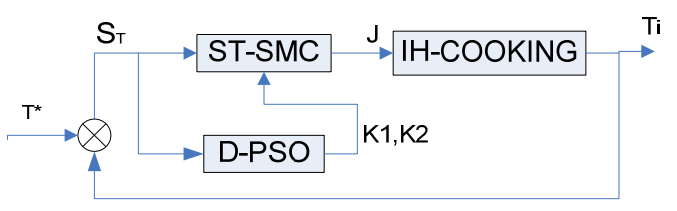

Figure 5. Block diagram of the ST-SMC based D-PSO for the cooking induction

\subsection{Super-twisting sliding mode control}

super-twisting sliding mode algorithms is one of the most important approaches and the most used among the family of HOSM algorithms, and it is designed to work and control nonlinear uncertain systems [15]. The principal idea of this algorithm is to drive the sliding variable and its derivative to zero in finite time, in order to be able to remove chattering effect due to the discontinuous control action.

The super twisting sliding mode control has been developed to work only with systems with relative degree equal to one, with the purpose to reduce the chattering while conserving the properties of a traditional sliding mode. One more advantage of this latter is that their implementation needs only the knowledge of the sign of the sliding variable (s) [16] which is given by

$$
\operatorname{sign}(s)=\left\{\begin{array}{clc}
-1 & \text { if } & s<0 \\
0 & \text { if } & s=0 \\
+1 & \text { if } & s>0
\end{array}\right.
$$

This latter algorithm has been represented by the control law, $u(t)$, which is composed of two parts. The first one is a discontinuous time derivative (u1) and the second part is a continuous function of the sliding variable (u2). The trajectories of the super twisting algorithm in the phase plane are characterized by a spiral movement around the origin of the sliding variable [17].

Let's Consider a nonlinear system given by (1) where $a, b, c$ are unknown functions, $x$ is the state, and $u, y$ are the control input and the controlled output respectively

$$
\frac{d x}{d t}=a(x, t)+b(x, t) u, y=c(x, t)
$$


The purpose is to get a control input function $y=f\left(y, y^{*}\right)$ which forces the system trajectories to the origin on the phase plane of sliding variable $y=y^{*}=0$ in a finite time.

The standard form of the control law to control the output $y$ in super-twist algorithm can be given by:

$$
\begin{aligned}
& u=K_{1}|s|^{r} \operatorname{sign}(s)+u_{1} \\
& u_{1}^{*}=K_{2} \operatorname{sign}(s)
\end{aligned}
$$

Where the sliding variable is is defined as:

$$
s=y^{*}-y
$$

$\mathrm{k} 1$ and $\mathrm{k} 2$ are controller gains $r=0.5$.

To drive the trajectories on to the sliding manifolds $\mathrm{s}^{\cdot}=0$ in finite time, the gains $\mathrm{k} 1$ and $\mathrm{k} 2$ must verify the following inequality:

$$
\alpha\rangle \frac{\Phi}{\Gamma_{m}}, \lambda^{2} \geq \frac{4 \Phi}{\Gamma_{m}^{2}} \frac{\Gamma_{M}}{\Gamma_{m}} \frac{\alpha+\Phi}{\alpha-\Phi}
$$

When using the super twisting control law, it is not necessary to know the time derivative information of the sliding variable [17]. Moreover, it is not necessary to know the information relating to the other system parameters. The latter allows the simplification of the computation of the controller and also the reduction of the number of sensors.

\subsection{Particle swarm optimization}

In 1995, Eberhart and Kennedy, developed an algorithm called pso, the idea of which was extracted from the movement of a group of animals such as a school of fish or a swarm of birds...etc [18].

The definition of this algorithm is similar to that of the genetic algorithm where the population is called "swarm" which includes a number of "individuals" called particles [19]. Moreover, each particle position is represented by a number of parameters to be optimized.

Furthermore, each particle of the swarm explore D-dimensional space in order to search the best position which give the best fitness function [20].

The best particle position that gives the best fitness value, named as (best), is known as the personal information of each particle [20]. On the other hand the best particle positions that give a best fitness function among all particles (pbest) is named as (gbest) [21].

D-PSO is one of the family of pso algorithms, and it is characterised by the use of a Time Varying cognitive (c1) and a social component (c2).This is developed for the purpose of improving the performance of standard PSO algorithm [12].

Let's consider $\mathrm{N}$ is number of particles, and $\mathrm{D}$ is the dimension of each particle, which represent the number of variables of the system.

The position and the velocity vector of the $\mathrm{N}$ particles at iteration $\mathrm{k}$ are respectively represented as

$$
\begin{aligned}
X_{i}^{k} & =\left[X_{i, 1}^{k}, X_{i, 2}^{k}, \Lambda, X_{i, D}^{k}\right] \\
V_{i}^{k} & =\left[V_{i, 1}^{k}, V_{i, 2}^{k}, \Lambda, V_{i, D}^{k}\right]
\end{aligned}
$$

Where $\mathrm{i}=1 \ldots \ldots \mathrm{N} \mathrm{J}=1,2 \ldots \mathrm{D}$

At each iteration $(\mathrm{k})$

a. A particle updates its position and velocity by the following equations[22-24]

$$
\begin{aligned}
V_{i j}^{k+1} & =W * V_{i j}^{k}+C_{1} * \text { rand }_{1} *\left(\text { pbest }_{i j}^{k}-X_{i j}^{k}\right)+C_{2} * \text { rand }_{2} *\left(\text { Gbest }_{j}^{k}-X_{i j}^{k}\right) \\
X_{i j}^{k+1} & =X_{i j}^{k}+V_{i j}^{k+1}
\end{aligned}
$$

b. The best position that gives the best fitness function of $i t$ particle is given as:

$$
\text { pbest }_{i}^{k}=\left(\text { pbest }_{i, 1}^{k}, \text { pbest }_{i, 2}^{k} \Lambda, \text { pbest }_{i, D}^{k}\right)
$$


c. The best particle that gives the best fitness function among all particles is given as:

$$
\text { Gbest }_{j}^{k}=\left(\text { Gbest }_{1}^{k}, \text { Gbest }_{2}^{k} \Lambda, \text { Gbest }_{D}^{k}\right)
$$

\begin{tabular}{|c|c|}
\hline$V_{i j}^{k}$ & is the velocity of particle $\mathrm{i}$ at iteration $\mathrm{k}$ \\
\hline W & is the weighting function \\
\hline$C_{1}, C_{2}$ & are the acceleration coefficients \\
\hline rand $_{1}$, rand 2 & are random numbers between 0 and 1 \\
\hline$X_{i j}^{k}$ & is the position of particle $\mathrm{i}$ at iteration $\mathrm{k}$ \\
\hline pbest $_{i j}^{k}$ & is the Best position of particle $\mathrm{i}$ at iteration $\mathrm{k}$ \\
\hline Gbest $_{j}^{k}$ & is the Best position of the swarm until iteration $\mathrm{k}$ \\
\hline
\end{tabular}

Where $\mathrm{c} 1, \mathrm{c} 2$ and $\mathrm{W}$ are computed by the following:

$$
\begin{aligned}
& C_{1}+C_{2} \geq 4.0 \\
& C_{1}=\left(C_{1 \max }-C_{1 \min }\right) \times(\text { iter } / \max \text { iter })+C_{1 \min } \\
& C_{2}=\left(C_{2 \max }-C_{2 \min }\right) \times\left(\text { iter } / \max _{\text {iter }}\right)+C_{2 \min } \\
& W=\left(W_{\max }-W_{\min }\right) \times\left((\max \text { iter }- \text { iter }) / \max _{\text {iter }}\right)+W_{\text {min }}
\end{aligned}
$$

Where:

ietr , maxiter are the current iteration number and the maximum number of iterations respectively

$C_{1 \max }, C_{1 \text { min }} \quad$ are the maximal and minimal cognitive coefficients respectively

$C_{2 \max }, C_{2 \min }$ are the maximal and minimal social coefficients respectively

$W_{\max }, W_{\min } \quad$ are the maximal and minimal weighting function respectively

At each iteration $(\mathrm{k})$, the position and the velocity of each ith particle are updated using (13-14),and then we evaluate the objective function [25]. The results are compared between: the new pbest (best position for the particle I at the current iteration) with the old Pbest (the best position for the particle i at iteration (k1)), then we select the optimal pbest. In the same way we compare the new Gbest with old Gbest, then we select the optimal Gbest. The flow chart of proposed technique is given in Figure 6.

\subsection{Application of D-PSO for ST-SMC gain parameters to induction cooking}

The induction cooking system is modeled by finite element analysis and the temperature was calculated in the bottom of the pan, as explained in section 3

A particle swarm optimization is used in this work in order to choose the optimum gain parameters of super-twisting sliding mode controller (K1, K2). Thereafter, at each iteration step, the optimized controller has been used to control the evolution of temperature on the bottom of the pan, as shown in Figure 5. In this work:

a. the optimization problem can be formulated by Minimizing the following fitness function

$$
f_{o b j}\left(K_{1}, K_{2}\right)=\sum_{i=1}^{N T}\left(\frac{T_{i}-T^{*}}{T^{*}}\right) \leq \varepsilon
$$

Where:

NT Is the total of number element of mesh

b. Each particle is represented by two parameters which, for the dimension of system $(\mathrm{D}=2)$, are

$$
K_{i}=\left\{K_{1}, K_{2}\right\}
$$

c. The best position that gives the best fitness function of $i t h$ particle is defined as

Int J Pow Elec \& Dri Syst, Vol. 11, No. 2, June 2020 : 1055 - 1064 


$$
\text { pbest }_{i}^{k}=\left(\text { pbest }_{i, K 1}^{k}, \text { pbest }_{i, K 2}^{k}\right)
$$

d. The best particle that gives the best fitness function among all particles is defined as

$$
\text { Gbest }^{k}=\left(\text { Gbest }_{K 1}^{k}, \text { Gbest }_{K 2}^{k}\right)
$$

A super twisting control algorithm is employed to control the output temperature of the system to the desired value, which need only the measurement of the temperature on the pan's bottom. For that purpose, The ST-SM temperature controller is given below:

$$
\begin{aligned}
& J=K_{1}\left|S_{T}\right|^{r} \operatorname{sign}\left(S_{T}\right)+J_{1} \\
& J_{1}^{*}=K_{2} \operatorname{sign}\left(S_{T}\right)
\end{aligned}
$$

Where the current density $\mathrm{J}$ is considered as the output of the ST-SMC controller. The sliding variable of the proposed controller is the temperature error

$$
S_{T}=T^{*}-T_{i}
$$

Where:

$T^{*}$ is the desired temperature.

$T_{i}$ is the measured temperature in the middle of the pan's bottom

$K_{1}, K_{2}$ Are gains parameters determined by D-PSO method

The structure diagram of the proposed methods (ST-SMC based D-PSO) and (ST-SMC based PSO) for the induction cooking system is summarized in Figure 7.
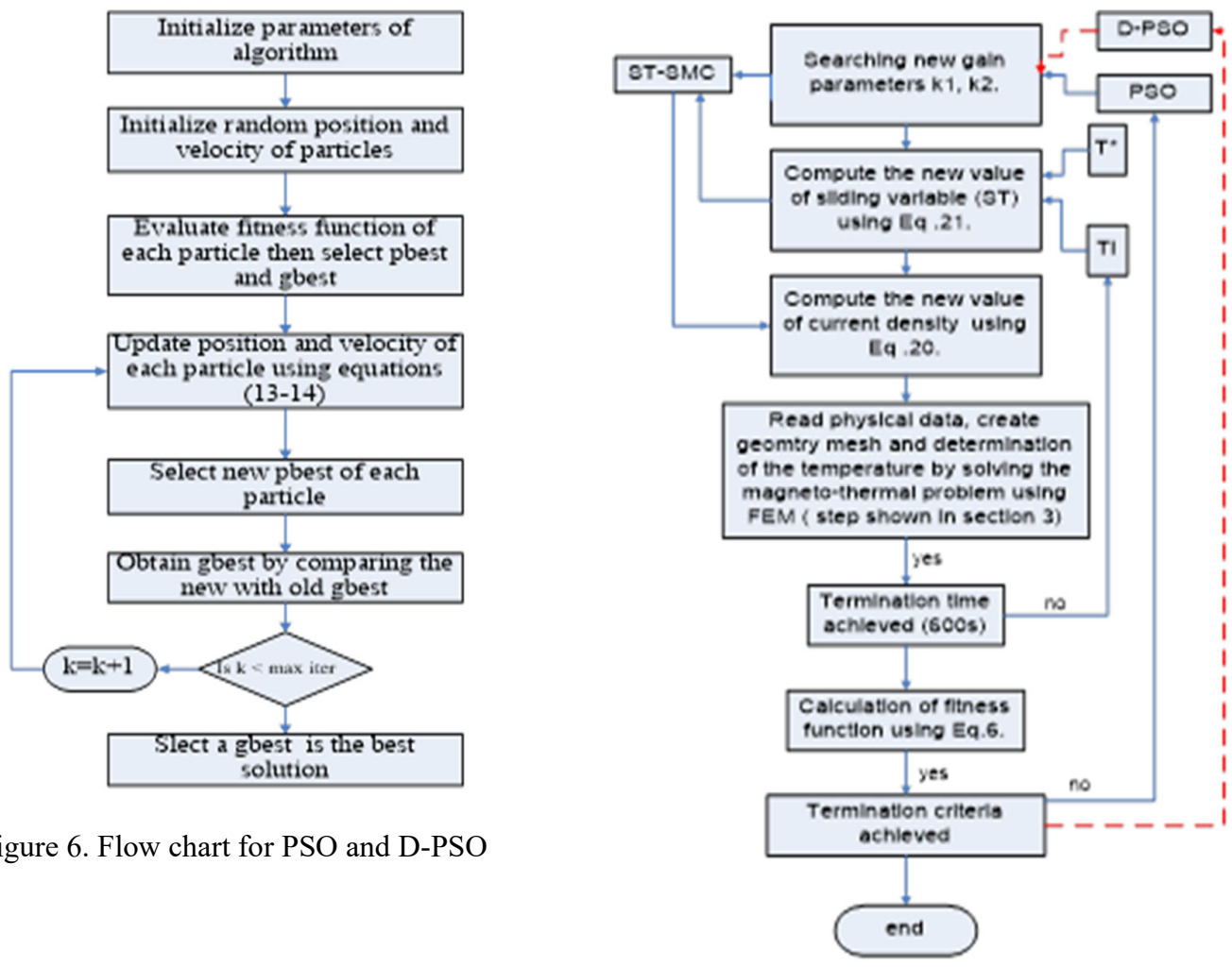

Figure 6. Flow chart for PSO and D-PSO

Figure 7. Flow chart for ST-SMC based D-PSO and PSO for the cooking induction 


\section{RESULTS AND DISCUSSION}

To prove the effectiveness of the ST-SMC controller method based on D-PSO algorithm designed to enhance the performance of the induction cooking system, we have used the MATLAB software. The simulation results of uncontrolled and controlled system are compared in terms of reference tracking, temperature evolution and robustness against the physical parameter variations (relative permeability, resistivity, Thermal conductivity....). The parameters of the D-PSO and PSO algorithms are shown in table 2.

Table 2. Parameters seting of D-PSO and PSO

\begin{tabular}{lcc}
\hline \multicolumn{1}{c}{ Parameters of algorithms } & PSO & D-PSO \\
\hline Population size & 12 & 12 \\
Max iteration number & 45 & 45 \\
C1min,C1max & $\mathrm{x}$ & $2.075,2.025$ \\
C2min,C2max & $\mathrm{x}$ & $2.025,2.125$ \\
W min, W max & $\mathrm{x}$ & $0.4,0.9$ \\
C1 & 2.05 & From eq 16 \\
C2 & 2.05 & From eq 17 \\
Weighting W & $\mathrm{x}$ & From eq 18 \\
\hline
\end{tabular}

Before the implementation of the controller, Figure 3, and Figure 4, shows that the temperature versus time on the pan's bottom exceeds the appropriate value of cooking, which is up at the Curie point $\left(760^{\circ}\right)$.

After the implementation of the proposed controllers (ST-SMC based D-PSO), and (ST-SMC based PSO), the optimum values obtained for super-twisting sliding mode gain parameters $(\mathrm{k} 1, \mathrm{k} 2)$, by both D-PSO and PSO algorithms, which maximizes the performance of methods are shown in Table.3, whereas the controlled temperatures are shown Figure 8.

Table 3. Gain parameters obtained by D-PSO and PSO

\begin{tabular}{llll}
\hline Algorithms & $\mathrm{k} 1$ & $\mathrm{k} 2$ & Value of fitness function \\
\hline ST-SMC -D-PSO & $-0.001 \mathrm{e} 5$ & $-1.1959 \mathrm{e} 5$ & 0.0793 \\
ST-SMC -PSO & $-0.0008 \mathrm{e} 5$ & $-1.2 \mathrm{e} 5$ & 0.0794 \\
ST-SMC & 500 & $-12.03 \mathrm{e} 4$ & $\mathrm{x}$ \\
\hline
\end{tabular}

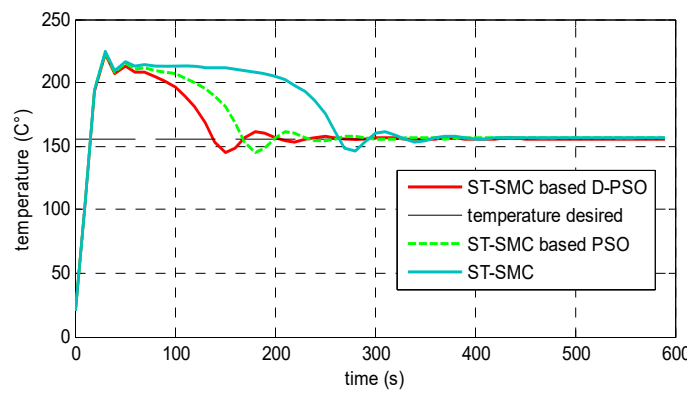

Figure.8. Temperature evolution versus time

From Figure 8, we can observe that the desired temperature value is reached, where the tracking error between the controlled temperature and desired are almost zero from 200s at $600 \mathrm{~s}$. This means that the chattering phenomenon becomes zero. It can be noted that the proposed method (ST-SMC based D-PSO), provides results that have a good accuracy and a more stable temperature than the other methods (ST-SMC and ST-SMC based pso).

The best fitness function value that gives the optimum gain parameters at each iteration step, for the two proposed methods, are shown in Figure 9. We can note from this figure, that the convergence by D-PSO, is more promising and faster than PSO algorithm, in term of minimizing fitness function value.

Int J Pow Elec \& Dri Syst, Vol. 11, No. 2, June 2020 : 1055 - 1064 


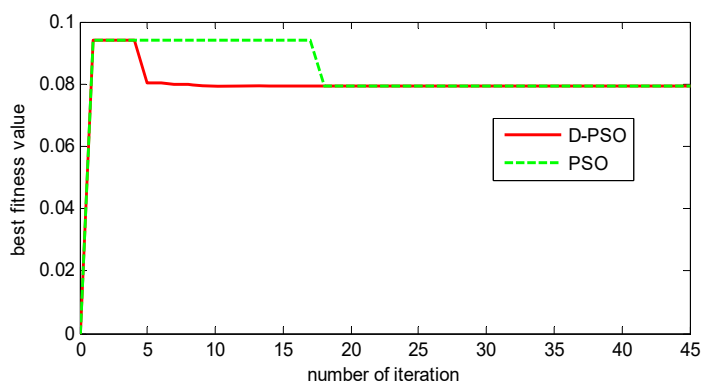

Figure 9. Best fitness value versus number of iterations

Figure.10 shows the comparison between simulation results before and after the application of the proposed controllers. From this figure we can see that the proposed methods give a good regulation of temperature versus time, despite the presence of large variations of physical parameters. We can see also from Figure 8 until Figure 10, that the ST-SMC with D-PSO give better resultants of temperature than the ST-SMC with PSO and ST-SMC, in term more accurate results, which significant that the ST-SMC-D-PSO is more performance then ST-SMC-PSO.

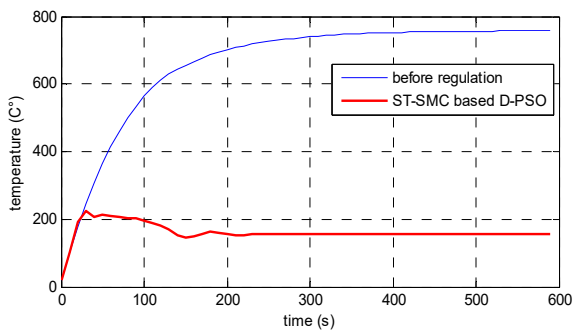

Figure 10. Temperature evolution versus time before and after applied ST-SMC based D-PSO

\section{CONCLUSION}

An optimization technique has been adopted for this work using the D-PSO to select the appropriate gain parameters, which improve the performance of the ST-SMC controller, where the improved ST-SMC is employed in order to control the temperature of the induction cooking device.

The main feature of this ST-SMC technique is the simplicity of implementation, and its robustness. This study shows that the proposed method (ST-SMC based D-PSO) gives a stable performance with a good temperature regulation, despite the presence of large variations in the physical parameters of the system, and also it gives a constant output cooking temperature $\left(150^{\circ} \mathrm{C}\right)$ which is the desired temperature.

\section{REFERENCES}

[1] F. Allaoui, A. Kanssab, M. Matallah, A. Zoui, and M. Feliachi, "Modelling and Optimization of Induction Cooking by the use of Magneto-thermal Finite Element Analysis and Neural Network," in Materials Science Forum, pp. 251-259, 2014.

[2] M. Feliachi and G. Develey, "Magneto-thermal behavior finite element analysis for ferromagnetic materials in induction heating devices," IEEE transactions on magnetics, vol. 27, pp. 5235-5237, 1991.

[3] Z. Dong, Y. Li, S. Zhang, and F. Shang, "Fuzzy temperature control of induction cooker," in IECON 2017-43rd Annual Conference of the IEEE Industrial Electronics Society, pp. 3051-3056, 2017.

[4] S. Janardhanan, M. un Nabi, and P. M. Tiwari, "Attitude control of magnetic actuated spacecraft using supertwisting algorithm with nonlinear sliding surface," in 2012 12th International Workshop on Variable Structure Systems, pp. 46-51, 2012.

[5] A. Bourouina, A. Djahbar, A. Chaker, and Z. Boudjema, "High order sliding mode direct torque control of a DFIG supplied by a five-level SVPWM inverter for the wind turbine," Elektrotehniski Vestnik, vol. 85, pp. 263-270, 2018.

[6] Z. Boudjema, R. Taleb, Y. Djeriri, and A. Yahdou, "A novel direct torque control using second order continuous sliding mode of a doubly fed induction generator for a wind energy conversion system," Turkish Journal of Electrical Engineering \& Computer Sciences, vol. 25, pp. 965-975, 2017.

Super-twisting sliding mode controllers based on D-PSO optimization for ... (Abdeldjalil Abdelkader Mekki) 
[7] M. K. Khan, K. B. Goh, and S. K. Spurgeon, "Second order sliding mode control of a diesel engine," Asian Journal of Control, vol. 5, pp. 614-619, 2003.

[8] E. Köse, K. Abaci, H. Kizmaz, S. Aksoy, and M. A. Yalçin, "Sliding mode control based on genetic algorithm for WSCC systems include of SVC," Elektronika ir Elektrotechnika, vol. 19, pp. 25-28, 2013.

[9] P. N. Menon and R. Anasraj, "Particle Swarm Optimized Sliding Mode Controller for an AC-DC Boost Converter," in 2014 3rd International Conference on Eco-friendly Computing and Communication Systems, pp. 277-281, 2014.

[10] Z.-m. CHEN, W.-j. MENG, J.-g. ZHANG, and J.-c. ZENG, "Scheme of sliding mode control based on modified particle swarm optimization," Systems Engineering-Theory \& Practice, vol. 29, pp. 137-141, 2009.

[11] S. V. Teja, T. Shanavas, and S. Patnaik, "Modified PSO based sliding-mode controller parameters for buck converter," in 2012 IEEE Students' Conference on Electrical, Electronics and Computer Science, pp. 1-4, 2012.

[12] V. Sankardoss and P. Geethanjali, "PMDC motor parameter estimation using bio-inspired optimization algorithms," IEEE Access, vol. 5, pp. 11244-11254, 2017.

[13] A. Kanssab, A. Zaoui, and M. Feliachi, "Modeling and optimization of induction cooking by the use of magnetothermal finite element analysis and genetic algorithms," Frontiers of Electrical and Electronic Engineering, vol. 7, pp. 312-317, 2012.

[14] J.-k. Byun, K. Choi, H.-S. Roh, and S.-y. Hahn, "Optimal design procedure for a practical induction heating cooker," IEEE transactions on magnetics, vol. 36, pp. 1390-1393, 2000.

[15] C. Lascu, I. Boldea, and F. Blaabjerg, "Super-twisting sliding mode control of torque and flux in permanent magnet synchronous machine drives," in IECON 2013-39th Annual Conference of the IEEE Industrial Electronics Society, pp. 3171-3176, 2013.

[16] J. Liu, S. Vazquez, L. Wu, A. Marquez, H. Gao, and L. G. Franquelo, "Extended state observer-based sliding-mode control for three-phase power converters," IEEE Transactions on Industrial Electronics, vol. 64, pp. 22-31, 2016.

[17] M. K. Khan, S. K. Spurgeon, and P. F. Puleston, "Robust speed control of an automotive engine using second order sliding modes," in 2001 European Control Conference (ECC), pp. 974-978, 2001.

[18] M. Alam, K. Kumar, and A. Mathur, "Economic load dispatch considering valve-point effects using time varying constriction factor based particle swarm optimization," in 2015 IEEE UP Section Conference on Electrical Computer and Electronics (UPCON), pp. 1-6, 2015.

[19] Y. Shi and R. C. Eberhart, "Empirical study of particle swarm optimization," in Proceedings of the 1999 Congress on Evolutionary Computation-CEC99 (Cat. No. 99TH8406), pp. 1945-1950, 1999.[20] S. Mandal, S. Ghshal, R. Kar, D. Mandal, and A. Shivare, "Swarm intelligence based optimal linear fir high pass filter design using particle swarm optimization with constriction factor and inertia weight approach," in 2011 IEEE Student Conference on Research and Development, 2011, pp. 352-357.

[20] M. Salim and M. Sarvi, "Induction Motor Speed Control Using Indirect Z-source Matrix Converter with PSO-PI Controller under Various Break Conditions," International Journal of Power Electronics and Drive Systems (IJPEDS), vol. 3, no. 1, pp. 41-52, 2013.

[21] F. A. Hasan and L. J. Rashad, "Fractional-order PID controller for permanent magnet DC motor based on PSO algorithm," International Journal of Power Electronics and Drive Systems (IJPEDS), vol. 10, no. i4, pp. 1724$1733,2019$.

[22] M. Bengourina, M. Rahli, S. Saadi, and L. Hassaine, "PSO based Direct Power Control for a Multifunctional Grid Connected Photovoltaic System, "International Journal of Power Electronics and Drive System (IJPEDS), vol. 9, pp. 610-621, 2018.

[23] Y. Ahmed and A. Hoballah, "Adaptive filter-FLC integration for torque ripples minimization in PMSM using PSO," work, vol. 3, pp. 4, 2019.

[24] S. W. Shneen, C. Mao, and D. Wang, "Advanced optimal PSO, Fuzzy and PI controller with PMSM and WTGS at $5 \mathrm{~Hz}$ side of generation and $50 \mathrm{~Hz}$ Side of Grid," International Journal of Power Electronics and Drive Systems (IJPEDS), vol. 7, pp. 173, 2016. 